\title{
Arnauld \& Andrade: dos projetores às galerias sem lâmpadas
}

Raul Antelo

UFSC

\section{Resumo}

O texto reflete sobre a condição da fotografia e sua relação com o rosto e o povo, a partir de encadear uma série de reflexões dos escritores Mário de Andrade e Celine Arnaud, e das diferenças entre os dois surgidas em relação à figura de Charlie Chaplin e seu filme $O$ garoto. Se percorrem os textos críticos produzidos, o conto "História de dados com”, e romance Macunaíma, de Mário de Andrade, e uma série de poemas de Celine Arnaud. O objetivo deste artigo é observar como certas cenas do filme permitem refletir sobre a construção de um novo tipo de imagem - o pós-cinema - que abre um campo superador das contradições entre "ser ou não ser", permitindo a configuração de "ser e não ser”, que Mário de Andrade desenvolvera, por exemplo, em Macunaíma.

Palavras-chave: Rosto; Povo; Charlie Chaplin; Pós-cinema.

\section{Resumen}

El texto propone una reflexión sobre la condición de la fotografía y su relación con el rostro y el pueblo, a partir de hilvanar una serie de reflexiones de los escritores Mário de Andrade y Celine Arnaud, y de las diferencias surgidas entre ambos en relación a la figura de Charlie Chaplin y de su filme Elpibe. Se recorren los textos críticos producidos para ello, a la narrativa breve "História com data", y la novela Macunaima, de Mário de Andrade, y una serie de poemas de Celine Arnaud. El objetivo del artículo consiste en observar de qué modo ciertas escenas de El pibe permiten reflexionar en torno a la construcción de un nuevo tipo de imagen -el post-cine- que abren un campo superador de las contradicciones entre "ser o no ser", permitiendo la configuración del "ser y no ser”, que Mário de Andrade desarrolla en su rapsodia Macunaíma.

Palabras clave: Rostro; Pueblo; Charlie Chaplin; Pos-cine. 
1. AGAMBEN, Giorgio.

Pulcinella ovvero Divertimento per li regazzi, 2015, p.113.

2. Idem. La comunità che viene, 1990, p.42.

\section{Apud HERKENHOFF,}

Paulo. "Fotografia: o automático e o longo processo de modernidade". In: TOLIPAN et al. Sete ensaios sobre o modernismo, 1983, p. 41.
Il non-vissuto ha due forme: il carattere e il fantasma. Il carattere è il guardiano della soglia che veglia a che il nonvissuto rimanga per sempre tale, imprimendone sul volto l'inconfondibile traccia (ciò che segna e caratterizza il nostro volto non è quel che abbiamo vissuto, ma quel che è rimasto non vissuto); il fantasma è il tentativo di vivere ciò che è rimasto non vissuto: esso manca ogni volta il suo scopo, perché il non-vissuto viene compulsivamente evocato proprio e soltanto in quanto inaccessibile. Pulcinella sfugge a entrambi: al carattere, perché rinuncia al volto per una maschera; al fantasma, perché si affida soltanto alla sua infantile smemoratezza. ${ }^{1}$

Nei balletti delle girls, nelle immagini della pubblicità, nelle sfilate delle mannequins si compiva così il secolare processo di emancipazione della figura umana dai suoi fondamenti teologici che si era già imposto su scala industriale quando, all'inizio del XIX secolo, l'invenzione della litografia e della fotografia aveva incoraggiato la diffusione a buon mercato delle immagini pornografiche: né generico né individuale, né immagine della divinità né forma animale, il corpo diventava ora veramente qualunque ${ }^{2}$.

Em "Questões de arte", um artigo programático escrito para o Jornal do Comércio (25 jul. 1921) e suscitado pelas esculturas de Victor Brecheret, Oswald de Andrade defendia a tese de que o artista é um ser de privilégio que produz um mundo "supra-terreno, antifotográfico, irreal", porém mundo existente, contudo, obviamente chocante, e por isso mesmo, profundo. Daí que o critério axiológico da proximidade ou semelhança com o natural fosse, a seu ver, "a maior vergonheira de uma cultura. Arte não é fotografia! Nunca foi fotografia! Arte é expressão, é símbolo comovido"’.

Dentre tantas outras oportunidades, tais como o conceito expressionista de primitivo, elaborado em oposição ao hierarquizante e desenganado Ortega y Gasset, ou mesmo nas considerações nos prefácios inéditos de Macunaíma, no sentido de ele ser, autonomamente, mais do que um símbolo e quase uma ação, Mário de Andrade basicamente coincide com Oswald, muito embora discrepe, em um ensaio para a Klaxon, logo a seguir, em 1922, das teorias da imagem e do sonho elaboradas pela poeta dadaísta Céline Arnauld. Retomemos, na íntegra, o comentário de Mário:

O garoto por Charlie Chaplin é bem uma das obras primas mais completas da modernidade para que sobre ele insista mais uma vez a irrequieta petulância de Klaxon. Celina Arnauld, pelo último número fora de série da revista Action, comentando o film com bastante clarividência, denuncia-lhe dois senões: o sonho e a anedota da mulher abandonada que por sua vez abandona o filho. Talvez haja alguma razão no segundo defeito apontado. Efetivamente o caso 
cheira um pouco à subliteratura. $\mathrm{O}$ que nos indignou foi a poetisa de Point de Mire criticar o sonho de Carlito. Eis como o percebe: "Mas Carlito poeta sonha mal. O sonho objetivado no film choca como alguns versos de Casimiro Delavigne intercalados ás Illuminations de Rimbaud. Em vez de anjos alados e barrocos, deveria simplesmente mostrar-nos pierrots enfarinhados ou ainda outra coisa e seu film conservar-se-ia puro. Mas quantos poemas ruins tem os maiores poetas".

Felizmente não se trata dum mau poema. O sonho é justo uma das páginas mais formidáveis de $O$ Garoto. Vejamos: Carlito é o maltrapilho e o ridículo. Mas tem pretensões ao amor e á elegância. Tem uma instrução (seria melhor dizer conhecimentos) superficial ou o que é pior desordenada feita de retalhos colhidos aqui e além nas correrias de aventura.

É profundamente egoísta como geralmente o são os pobres, mas pelo convívio diurno na desgraça chega a amar o garoto como a filho. Além disso já demonstrara suficientemente no correr da vida uma religiosidade inculta e ingênua. Num dado momento conseguem enfim roubar-lhe o menino. E a noite adormecida é perturbada pelo desespero de Carlito que procura o enjeitado. Com a madrugada, chupado pela dor, Carlito vai sentar-se à porta da antiga moradia. Cai nesse estado de sonolência que não é o sono ainda. Então sonha. Que sonharia? O lugar que mais perlustrara na vida, mais enfeitado, ingenuamente enfeitado com flores de papel, que parecem tão lindas aos pobres. E os anjos aparecem. A pobreza inventiva de Carlito empresta-lhes as caras, os corpos conhecidos de amigos, inimigos, policiais e até cães. E os incidentes passados misturam-se às felicidades presentes. Tem o filho ao lado. Mas a briga com o boxista se repete e os policiais perseguem-no. Carlito foge num vôo. Mas (e estais lembrados do sonho de Descartes) agita-se, perde o equilíbrio, cai na calçada. E o sonho repete o acidente: o policial atira e Carlito alado tomba. O garoto sacode-o, chamando. É que na realidade um policial chegou. Encontra o vagabundo adormecido e sacode-o para acordá-lo. Este é o sonho que Celine Arnauld considera um mau poema. Como não conseguiu ela penetrar a admirável perfeição psicológica que Carlito realizou! Ser-lhe-ia possível com a mentalidade e os sentimentos que possuía, no estado psíquico em que estava, sonhar pierrots enfarinhados ou minuetes de aeroplanos! Estes aeroplanos imaginados pela adorável dadaísta é que viriam forçar a intenção da modernidade em detrimento da observação da realidade. Carlito sonhou o que teria que sonhar fatalmente, necessariamente: uma felicidade angelical perturbada por um subconsciente sábio em coisas de sofrer ou de ridículo. O sonho é o comentário mais perfeito que Carlito poderia construir de sua pessoa cinematográfica: não choca. Comove imensamente, sorridentemente. E, considerado à parte, é um dos passos mais humanos de sua obra, é por certo o mais perfeito como psicologia e originalidade ${ }^{4}$.

4. ANDRADE, Mário de. "Ainda O Garoto". Klaxon, 1922, p. 13-4. 
Sabemos que a fotografia é, de algum modo, o lugar do Juízo Universal; ela representa o mundo no ponto do irreversível. Mas essa questão suscita sempre múltiplas interpretações. A primeira conseqüência que podemos tirar da leitura de Andrade é que sua diferença com Arnauld reside, basicamente, em retirar do cinema uma lição estrutural, ao passo que a poetisa explora nele as desmontagens disparatadas do dadaísmo que, a seu ver, em $O$ garoto, faltam. Com efeito, o elogioso resumo que Mário nos dá de $O$ garoto teria sido transformado e apropriado, por ele mesmo, paralelamente, em escrita ficcional. Em "História com data", um conto de 1921, Andrade insere no meio de uma discussão sobre identidade e técnica a respeito de Azoé (a vida nua), um pastiche intercalado que simula aquilo mesmo que, na narrativa principal, vinha se desenvolvendo. No conto enxertado de Mário é um motorista quem cai no sono e delira uma série de bizarros cruzamentos e desencontros dignos de um folhetim mirabolante. Veja-se que, em O garoto, Mário de Andrade justamente admirou que a personagem de Chaplin caísse "nesse estado de sonolência que não é o sono ainda". E sonha então, infantil ou primitivamente, com anjos e flores de papel. Tal como no conto de Andrade, a pobreza inventiva do motorista (aliás, a profissão desejada por Ellis, "o garoto" protagonista de “Túmulo, túmulo, túmulo”) empresta-lhe a essas construções as caras, os corpos conhecidos de amigos, inimigos, policiais e até mesmo dos cães que latem à passagem da comitiva, de tal sorte que os incidentes passados misturam-se às felicidades presentes e Carlito, finalmente, "foge num vôo", por meio da mesma ironia dos desastres que vitima Alberto Figueiredo Azoé no conto de Primeiro andar.

Por sinal, o próprio Andrade associa, na resenha de $O$ garoto, a experiência interdiscursiva e polifônica como algo assemelhado ao sonho de Descartes. Se estamos lembrados, no terceiro dos sonhos de 10 de novembro de 1619, Descartes encontra-se diante de uma enciclopédia e, quando estende a mão para pegá-la, depara-se, porém, com outro livro, o Corpus poetarum. Abre ao acaso o livro e encontra o "Idílio XV" do poeta romano Ausônio, o mesmo que tornara famoso o tópico do carpe diem. O primeiro verso chama-lhe logo a atenção: Quod vitae sectabor iter? (Que caminho percorrer na vida?). Surge então um desconhecido e lhe aponta um outro poema de Ausônio, a quarta écloga intitulado Est et Non (Est et Non cuncti monosyllaba nota frequentant, ou seja, todo mundo usa estes monossílabos), que toca nos dilemas de um pitagórico, ser ou não ser. Mas quando, finalmente, Descartes tenta segurar o Corpus poetarum, ele desaparece. Em seu lugar, resta-lhe o volume da enciclopédia, desprovido, porém, dos sonhos. A lição coincide com a do pós-poema de Murilo Mendes. Não se trata de ser ou não ser, que é, de resto, a dialética macunaímica, o desafio antropófago. Trata-se 
de ser e não ser. Est et non igitur. O sonho de $O$ garoto é assim uma figuração da pós-poesia (e do pós-cinema) que abre para Mário de Andrade a alternativa de uma rapsódia estrutural, algo que Céline Arnauld interpretaria como alternativa conciliatória, meramente reativa. "História com data" preanuncia assim Macunaíma, como chave do moderno-nacional, da mesma forma que O garoto fornece a chave neutra, a terceira pessoa, "o maltrapilho e o ridículo", que refere experiências da vida anônima de massa. É por sinal o paradigma com que Mário construiu os Contos de Belazarte. Carlito, num sonho, me contou...

Mas antes de avançar, valeria a pena nos determos em Céline Arnauld, a antagonista de Mário nesse desafio onírico. Céline Arnauld (1885-1952), nascida na Romênia como Carolina Goldstein, foi uma das figuras mais raras do dadaísmo, equilibrando-se sempre entre poesia e cinema. Casada com Paul Dermée, o diretor da revista Esprit Nouveau, cujos artigos sobre estética Mário lia e estudava com dedicação, Céline colabora ativamente em Dadaphone, 391 e Littérature. É uma das artistas que rubricam L'œil cacodylate (1921), a tela com colagens e cartões de Francis Picabia (148,6 x 117,4cm, Musée National d’Art Moderne, Paris), talvez a que melhor ilustra a ideia de société anonyme e criação coletiva. Ainda com Picabia, Arnauld redige Pilhaou-Thibaou, polêmico texto contra Breton e o próprio dadaísmo. Em muitos dos seus poemas dadá, a sensibilidade de Arnauld leva-a a problematizar a hegemonia do olhar masculino na partilha de atribuições e responsabilidades que tornam o mundo moderno um mero parque feérico, nem por isso menos violento. "Luna park", publicado em sua revista Projecteur (n 1, 21 maio 1920, p. 7) nos fala de uma placa ótica, semelhante aos artilúgios de Duchamp e Man Ray, colada às próprias costas, que desvenda o horóscopo fotóforo de passados dias inglórios.

\footnotetext{
Sinistre étalage de cette glace optique plaquée sur mon épaule photophore horoscope des mauvais jours tatouage de mes ennemis submergés au fond des tristes réservoirs cristallisés par des éclairs fuyants.
}

A própria voz poética define-se, no fim do poema, como "le reflet éphémère / de projecteur / aubade à porte-voix". E, em outro poema, "Périscope", até mesmo o poderoso monstro, o basilisco, cai fulminado pelo próprio olhar.

La rapière s'est plantée dans le limon tatoué de la taupinée maison faite à tátons avec l'aide du violon après le solstice la mort des chanteurs des buissons et des javelles cathédrales séchées par des chansons. 
5. ARNAULD, Céline.

"Périscope". 391, 1920, p. 6

6. "El ardor accional que poseen los hipervitalistas dadás demuestra que, en efecto, y de acuerdo con unas palabras epistolares de Tr. Tzara -que me dirigió desde Zurich en octubre de 1919_, 'Dada antes que una escuela literaria o artística, es una intensa manera de vivir'. Y agregaba: 'Sin embargo, para guardar una cierta continuidad de tendencias que no se hallan reglamentadas, DADA cambia y se multiplica constantemente'. Una lluvia de Revistas caracteriza su época más expansiva. Cada escritor del grupo llega a poseer su órgano de expresión personal. Paralelamente al grito "todo el mundo es director del Movimiento Dadá", dicen "todos los poetas dadaístas son directores de Revistas". Y en efecto, durante el mes de abril y ornando el papel timbrado del Movimiento DADA—donde aparece como central París y ciudades sucursales Berlín, Ginebra, Madrid, Roma, NewYork y Zurich—se anuncian las siguientes Revistas: Dada dirigida por Tzara, Dd 04 B.2 por Ribemont-Dessaignes que sólo contó un número, Littérature la más severa y consolidada que nacida cubista desvióse hacia Dada por Aragón, Breton y Soupault; Ipeca, M'amenez. y Projecteur, de Céline Arnauld que sólo florecieron una vez; Proverbe, de Paul Eluard, que cuenta hasta cinco números; Cannibale, de Picabia, muy pintoresca, y $Z$, de Paul Dermé, que murió nonnata. El carácter deliberadamente efímero y esporádico de la mayoría de estas publicaciones, ha hecho que hoy, al cabo de unos meses, sólo subsistan las más arraigadas y de una justificación probada: como Littérature —núcleo de vanguardia, ecléctico y selecto-
J'ai vu et j'ai compris l'erreur de toute une doctrine le message lyrique du mime et la nuit se prolongea gaie et éternelle dans les yeux des oiseaux voyageurs.

Quand les boissons des cabarets peints passaient avec leurs lanternes par la forêt les oiseaux volaient des morceaux de lumière et les cachaient dans leurs nids.

Indigestion d'étoiles intoxication lunaire et la fête commença sous le clocher que traverse l'éclair en sourdine. Tous les nids s'étaient allumés et dans les yeux se mourait le dernier rayon de la spontanéité.

Affolés les criquets pélerins se posèrent à trois au bord du croissant de la lune descendue par sympathie sur les seins d'Argine.

Ah le mime a parlé la rapière plantée dans les mots du solstice en rire qui vient de naître - Le basilic tomba foudroyé par son propre regard. ${ }^{5}$

Mas, além do periscópio ou pariscopio dadá, Céline Arnauld se via ela própria como um projetor. É sintomático, portanto, o lacônico prospecto de sua revista, Projecteur, que assim se apresenta:

Projecteur est une lanterne pour aveugles. Il ne marchande pas ses lumières, elles sont gratuites. Projecteur se moque de tout: argent, gloire et réclame — il inonde de soleil ceux qui vivent dans le froid, dans l’obscurité et dans bennui. Drailleurs, la lumière est produite par une pullulation madrépodique dans les espaces célestes.

Dessa revista Projecteur houve apenas um número. Mas, mesmo efêmera, ela deixa um rastro fecundo para nós. Na discussão sobre seu nome, Arnauld cogitou duas outras alternativas, M'amenez-y e Ipeca. Guillermo de Torre chegou mesmo a afirmar que todas três existiram ${ }^{6}$. Não nos consta. Examinemos os nomes. O primeiro título faz referência a M'amenez-y (1920), o óleo de Picabia conservado no MoMA (129.2 x $89.8 \mathrm{~cm})$ e a um complexo jogo onomástico nele incluído. Vejamos. Em vez de usar o corriqueiro óleo de linhaça (l'huile de lin), que fixa as pinturas, a tela diz ter sido realizada com óleo de rícino (l'buile de Ricin), a famosa substância tóxica usada pelos fascistas italianos. E em vez de ter sido feita convencionalmente em um atelier d'artiste, a tela exibe outra inscrição, Ratelier d'artiste, ou seja, suporte ou grade de artista. A tela suporta tudo aquilo que nela quisermos pendurar. Por último, Peinture crocodile associa a pintura à exagerada falsidade das lágrimas de crocodilo. Porém, o disparate mor é o próprio título da peça, que revela a atração de Picabia, e mesmo do grupo dadaísta, pelas conexões automáticas e mecânicas, com a menor expressividade envolvida. Assim, M'Amenez-y significa levem-me junto, mas paronomásicamente soa como minha amnésia.

Longe de querer estabelecer uma identidade ou personalidade, um caráter público e coerente, os artistas dadá 
depositam no esquecimento (na emese e não na incorporação) uma alternativa inaugural e sensível. Mas não param aí as conexões. O ready-made associa-se a outra tela de Picabia, Le double monde (1919), em que a mesma frase, m'amnenez-y, cruza, horizontalmente, o enunciado vertical com que Duchamp nomeou sua Mona Lisa apropriada, L.H.O.O.Q. A amnésia se interpõe na fogosa cerimônia erótica e nos mostra que já não estamos diante de obras, senão de textos, de in-operações do sistema simbólico. Desoeuvrements.

Assim, o poema de Céline Arnauld sobre o escaravelho ou caruncho volta-se também, sintomáticamente, aos mosquitos domésticos (meio estoque) que Rrose Sélavy exigia, para a cura do azoto, na Côte d'Azur. Diz o poema de Arnauld:

\author{
Tout près de l'angoisse \\ Les moustiques en folie \\ Autour de l'ampoule la mort de l'oiseau \\ Dans l'atmosphère les atomes en oripeaux \\ senvolant avec la pluie \\ traînent dans une parade novice \\ des moulures harmoniques \\ Tandis quau pays de Mendoza \\ Les mandores chassent les chevaux de bois \\ à travers champs \\ et les grandes roues sont poussées \\ par des éléphants \\ Au Collège de France \\ ils ssendorment sur les bancs \\ Moi je ne sais rien que maudire \\ et divaguer contre l'hypothèse...?
}

O insólito cortejo puxado por elefantes une Mendoza (extremo ao qual chega, por sinal, Macunaíma) e os bancos universitários do Quartier Latin. Mas esta anacrônica conexão do double monde nos leva a considerar, por último, o terceiro nome que surgira para batizar a revista e sua própria poética, Ipeca. Trata-se de uma planta rubiácea, a ipecacuanha (nome de origem araucana) ou raiz-do-Brasil, que é um poderoso emético já descrito no século XVII pelo holandês Piso, em sua História natural do Brasil’. Em suma, que tanto um quanto outro título descartado nos ilustram o sentido em que devemos tomar o projecteur. ele não é sinal de tropicalismo antropófago e modernólatra e sim de emetismo contemporâneo e anarquisante. É esse projetor o que nos exibe um filme insólito em que, na autópsia de uma borboleta, que é apenas o estado adulto da termita que carcomia as madeiras no poema de "Les Ronge-Bois", surge a enumeração caótica do inconsciente, tal como a veríamos sete anos mais tarde em $O$ cão andalur: más las primitivas Dadá y 391 , órganos personales de Tzara y Picabia, respectivamente, y a su vez integrales del Movimiento en conjunto". TORRE,

Guillermo de. "Gestos y teorias del dadaísmo". Cosmópolis, $\mathrm{n}^{\mathrm{o}} 26,1921$, p. 344 . O texto foi mais tarde incorporado à sua canônica história das literaturas de vanguarda.

7. ARNAULD, Céline. "Les Ronge-Bois". Projecteur, Paris, 1920, p.11.

8. THIEBLOT, M.J. Poaia, ipeca, ipecacuanba. A mata da poaia e os poaieiros do Mato Grosso, 1980. 
9. ARNAULD, Céline. "Envoi du Japon”. 391, 1921, p. 5.

10. "The rhetoric of rage, though, is mixed with inventiveness and unique visualizations. Arnauld's rejection of the (hostile) gaze, reduced to onion peelings, has a sensuous and pre-feminist edge. Most compellingly, she looks forward to an alternative to the status quo: a 'filmed song', a notion which suggests the fusion of word and image, as well as music, of sight and sound. This art form will have the power to strangle and kill the believers and belief in the present situation, the 'stupid comedy'. Such radical potential is emphasized by the term 'rocketfilm', a neologism that points to the new technologies of travel and exploration, and pairs its inherent idea of movement, transport and rapidity with a filmic vision. Interesting, too, is its interrogation of the role of the writer. This text's point of departure is the cultural establishment, the Arts. In a manifesto, Ombrelle Dada (Dada Parasol) for example, printed in Littérature no. 13, May 1920, she mocks 'Aaart' and 'Poéésie', aligning herself clearly with the Dadaist rejection of the pretensions attached to high culture (the elongated vowels might be interpreted as renderings of a drawling voice). In Dangereux, she, the writer, is the inventor of this new crossgenre, multi-media weapon. It is, moreover, to be screened at a cinema named after her, the Céline Arnauld cinema. That she uses her pen-name here, rather than that of Dada, is not untypical of the ironic self-pronouncements made by her male colleagues, but can be read equally as a semi-serious assertion of her creative power as an individual writer. It might also suggest that she is seeking
Le D' Li-ti-pi m'avait invitée à assister à une autopsie. Cela se passait à la morgue de Tchiou-Chang. Sur la table on avait étendu un énorme papillon. On trouva caché derrière ses ailes : une locomotive, quatre martyrs, un sucre d'orge, un curé, un flacon d'aspyrine, une étoile, un mouton et un serpent, un empereur, un homme, un parapluie, une lune et huit soleils, enfin toute une cour, à qui il portait ombrage ! "Alors le papillon soulagé se mit à voler, à la grande joie et au grand chagrin de ceux qui le croyaient mort". ?

Logo no primeiro número de Cannibale, abril de 1920, em "Dangereux", Arnauld qualifica seus textos de chansons filmées, composições virulentas que se exibiam no Cinema Céline Arnauld, isto é, a própria artista transformava-se em opéra fabuleux (Rimbaud, na Alquimia do verbo). Ruth Hemus vê, nesse gesto, uma disputa de gênero, num ambiente fortemente fechado e hostil para uma mulher artista ${ }^{10}$. Uma declinação do caráter, uma ativação do fantasma. Mas mesmo radical, o gesto conota também uma total suspensão dos gêneros, não apenas estéticos como também sexuais. Nesse sentido, Céline Arnauld considera um filme de Douglas Fairbanks um autêntico poema em prosa, o gênero híbrido e paradigmático da modernidade, como híbrido e ambíguo eram não só o Zorro quanto o autor que o interpretava ${ }^{11}$ :

Le cinéma a souvent besoin d'indulgence et de générosité de la part même des artistes. Il n'est déjà plus un art muet; il réunit tout : visions, images, pathétique, tendresse, lyrisme, etc. Tout y est vivant, ardent, actif, comme la jeunesse. Le signe de Zorro est aussi beau qu'un poème en prose. Le drame y est enveloppé d'un voile poétique. Douglas dans son jeu souple et merveilleux réunit le clown, l'acrobate, le poète, le justicier. Il passe si complètement d'un jeu à l'autre qu'il est impossible de le reconnaître dans les deux personnages antipodiques. ${ }^{12}$

É essa definição anestésica, anônima e anárquica que leva Céline Arnauld a fazer objeções a $O$ garoto. Retomemos o artigo dela para Action que suscita a polêmica com Mário de Andrade. A poeta começa argumentando que

On a beaucoup vanté ce film avant même qu'il ne fût projeté. Evidemment, comme publicité c'était réussi ; seulement on a toujours une certaine déception lorsqu'on s'aperçoit qu'au lieu du château promis on ne vous offre qu'une cabane. Non pas que la cabane déplaise, mais l'imagination a travaillé et s'est formée aux promesses - et le public ne veut pas rêver au cinéma ; il veut voir des réalités, les vivre et en emporter à la fin du spectacle non pas l'oubli immédiat, mais un souvenir qui entrera dans sa vie comme un rayon qui se poserait sur le bord de sa fenêtre et y resterait éternel et immobile ${ }^{13}$. 
Arnauld busca em $O$ garoto um rayon do seu projecteur iconoclasta, um fragmento do opéra fabuleux que ela mesma espera da Aarte. Ao não encontrá-lo, decepciona-se.

Ce fut la déception que j'éprouvai en voyant Le Gosse, parce que je m'attendais à un enrichissement beaucoup plus grand de la manière habituelle de Charlot. Or, dans Le Gosse, Charlie Chaplin - (à part une tentative romantique de mauvais goût) - reste celui que nous avons autres chefs-d'oeuvre.

Mas o maior incômodo, talvez, resida em que, através de uma saída conciliatória, é a humanidade do artista que sai prejudicada. Humano, humanismo não podem ser apenas questões letradas; tais conceitos devem ser entendidos como uma via efetiva de changer la vie. Por isso Arnauld é cuidadosa ao ponderar que, como em "Túmulo, túmulo, túmulo",

La paternité de Charlot n'est pas une mystification ; la douleur qu'il éprouve à l'enlèvement de l'enfant est tellement vraie que l'on est heureux de penser qu'elle n'est pas réelle, car on ne voudrait pas voir souffrir le généreux Charlie Chaplin qui a donné tant de lui-même à l'humanité par la variété de son jeu de psychologue railleur, se raillant lui-même, et toutefois restant humain. J'insiste sur cette humanité, car il y a tant de clowns qui font rire, tant de mauvais films comiques, dont l'esprit manque si complètement de saveur que l'on en est plus énervé ou amusé. ${ }^{14}$

Mário de Andrade destaca Céline como autora de Point de Mire. Ao refutar suas ideias, todavia, Mário não podia desconhecer a opinião de Antonin Artaud, que Action publicara logo após a Semana de Arte Moderna:

Point de mire, par Céline Arnauld. Le monde vu du fond de la mer. Si vous n'êtes arbre à corail ou madrépore, vous ne pouvez rien comprendre à l'art de Céline Arnauld. Il faudrait en plus être un arbre à corail intelligent et qui pense. Un poème comme "Jeu d'échecs" ne se peut aborder de front. Il y faut une âme à l'instar. On espère peut-être de nous une explication logiquement raisonnable, une coordination raisonnée de ces poèmes! Il n’y en a pas. Céline Arnauld pense par association d'idées. Une image appelle une autre image d'après des lois qui sont les lois même de la pensée. Chaque poème est un corps complet et parfaitement organisé auquel des nécessités intérieures et lointaines imposent sa forme et sa dimension. Ex. : "Jeu d'échecs". Mais, avant tout, Céline Arnauld ne fait pas de littérature. Nous ne sommes pas pour les règles. Mais plus une littérature se passe de règles, plus elle a besoin de reposer sur la vie, de se modeler sur la vie, de s'infuser de la vie. Si aux yeux de certains la littérature d'à présent n'apparait plus que to break through the restrictions of literature, above all in the light of new technologies that allow for movement and sound. Dangerenx is a modern, mental picture, which draws attention to film - and to the experience of cinema, in particular - as a potent medium for expression and cultural change. In opposition to stagnation, it proposes a powerful new way of seeing". HEMUS, Ruth.

"Dada's Film-Poet: Céline Arnauld". In: TOWNSEND, Christopher; TROTT, Alex \& DAVIES, Rhys. Across the Great Divide. Modernism's Intermedialities, from Futurism to Fluxus, 2014, p.71. Poder-se-ia pensar Aaart como uma manifestação da anti-filosofia de Tzara que, em última análise, levará Lacan a denominar o objeto causa do desejo de objeto a.

\section{Heide Schlüpmann} argumenta que o gender trouble é um dos motores da comédia nos primórdios do cinema. SCHLÜPMANN, Heide. The uncanny gaze: the drama of early German cinema, 2010, p.51-65.

12. ARNAULD, Céline. "Le cinema. Le signe de Zorro". Action, Cabiers individualistes de Philosophie et d'art, 1921, p. 4.

13. Idem. "Le cinema. Le gosse". Action, "Hors-Série", p. 4.

14. Ibidem, p. 4-5. 
15. ARTAUD, Antonin. "Point de mire par Céline Arnauld". Action: Cabiers individualistes de Pbilosophie et d'art, 1922 , p.7. comme une mandarinade de lettrés décadents, la faute en est à quelques artificiels assembleurs d'images mécaniques, posées là comme des papillons tout faits. Mais la poésie de Céline Arnauld est une explosion d'ardentes sèves. C'est la vie elle-même qui pousse au dehors des efflorescences si nourries: c'est comme un brasier d'images : "Voici venir habillées d'austères musiques les fanfares du soir" ou "Le cortège de ses mains jointes en fougères stellaires". Un poème de Céline Arnauld a une couleur de cendre verte et de piment violet, et de toutes les choses en général qui font penser à ces clowneries merveilleuses et autres parades foraines dont s'enchantent les grands enfants. Le recueil est précédé d'un portrait de Céline Arnauld par Halicka qui est comme une classification de son âme ${ }^{15}$.

Antonin Artaud compreende corretamente que a estética de Arnauld é claramente pós-metafórica e anti-mimética. Suas imagens, vindas do fundo dos abismos (ela mesma as define como pullulation madrépodique), não operam por semelhança com o natural, senão que, por reverberação, uma imagem puxa outra imagem, conforme as regras associativas do inconsciente e esta característica permite a Artaud lançar sua definição mais bombástica, "Céline Arnauld ne fait pas de littérature", conceito que ficaria reservado a esses simplórios montadores de imagens mecânicas, que posam como borboletas artificiais, de puro enfeite. Artaud, pelo contrário, considera o trabalho de Céline Arnauld como uma explosão, um fogaréu de imagens que, por lógica, acaba se concentrando em cinza esverdeada, potentes sobrevivências de outrora, maravilhosas clowneries e cortejos de feira, que fazem as delícias dos garotos já adultos. Artaud intui algo que depois leríamos nos ensaios de Benjamin ou Agamben, que o sujeito fotografado exige algo de nós, num sentido que não deve ser confundido com uma necessidade factual. Muito embora o rosto fotografado permaneça hoje anônimo, mesmo assim, ou talvez por isso mesmo, esse rosto exige sempre um nome, uma memória.

Mário de Andrade, evidentemente, não poderia ir tão longe quanto Artaud avança em sua leitura da poeta-cineasta. Contudo, a polêmica com Céline Arnauld ainda sustenta um ensaio mais ambicioso de Mário, estampado no primeiro número da revista carioca Espirito Novo, em 1934, em que destaca o fato de Carlito ter composto "uma cara decididamente caricatural". Mas o que mais espanta nessa criação é que "todo o efeito dela é produzido diretamente pela máquina fotográfica”. E explica:

Carlito conseguiu lhe dar uma qualidade anticinegráfica, a que faltam enormemente as sombras e principalmente os planos. E é por isso em principal que a cara dele é cômica em si, contrastando violentamente com os outros rostos que aparecem no écran, e que a gente percebe como rostos da vida real. 
Nesse sentido, atrás do palhaço está o ser que finge de palhaço, que é, entretanto, alguém profundamente trágico, em função da excepcionalidade que carrega consigo. $\mathrm{E}$ isto leva Mário a aventar a hipótese da existência de dois cinemas: o cinema com criação, isto é, o cinema-arte e o cinema com sensualidade, isto é, o cinema-comércio. È a mesma diferenciação aliás que seria teorizada por Jean Cocteau ${ }^{16}$ e Pier Paolo Pasolini ${ }^{17}$. A superioridade de Carlito, a seu ver, não vem de dados naturais e muito menos da máquina fotográfica. Não é um fenômeno plástico, mas um elemento de ordem psicológica, que é sempre uma superfetação. ${ }^{18}$ Aquilo que permanece nos traços (nos vincos de um rosto) não é o vivido mas o que permaneceu sem ser vivido. Mário de Andrade afasta-se assim, delicadamente, de sua anterior defesa do humanismo e postula, entretanto, que Carlito (como Belazarte ou Chico Antônio) são seres cindidos, o homem qualquer, a manifestação da Coisa, em todos seus atributos. Trata-se de um novo paradigma, que conheceria aliás sua mais completa realização nos dias de hoje, e em que nenhum dos aspectos parciais de um fenômeno constitui per se diferença identitária capaz de ser sintetizada e estabilizada. Aquilo que define a singularidade qualquer é, ao contrário, a indiferença com relação à propriedade, de tal modo que ela se torna amável na mesma medida em que dessubjetivada ${ }^{19}$. Nos primórdios do cinema, o corpo dos atores funcionou como campo de uma inquietante profecia acerca da evolução da própria nudez na sociedade contemporânea, a tal ponto que, atualmente, quando se completa sua dissolução, o ser do homem, desprovido de qualquer hipóstase metafísica, como ainda era o Sein de Keyserling, em que Mário de Andrade baseou-se para compor Macunaíma ${ }^{20}$ e, ao mesmo tempo, carente de modelos teológicos para redefinir a vida, ainda precisa pesquisar sua própria consistência genérica para além da persona ético-teatral que lhe deu sustentação séculos afora ${ }^{21}$. Corpus poetarum.

Céline Arnaud nos dizia que há tantos palhaços, tantos filmes cômicos chinfrins em que não se encontra mais qualquer sabedoria que isso deixa a gente sem graça; por isso, a cara de Carlito talvez seja o único (o último) lugar impenetrável, onde de fato domina o silêncio. Enquanto o caráter deixa, no rosto, vestígios e marcas de coisas não ditas, enquanto a face do animal parece sempre prestes a proferir alguma verdade, o rosto humano, ou melhor, a fotografia do rosto, seu fantasma, abre o próprio rosto ao silêncio, que é, em última instância, o único lugar do homem².

Capta-se, portanto, na fotografia, na tomada cinematográfica (aliás, antifotográfica para Oswald, anticinegráfica para Mário), uma verdadeira tragicomédia da aparência, uma vez que o semblante descobre-se na medida em que se disfarça e ele simu-
16. COCTEAU, Jean. Poética del cine, 2015.

17. PASOLINI, Pier Paolo. "A poesia no cinema novo". Revista Civilização Brasileira, p. 267-287, 1966.

18. ANDRADE, Mário de. “Caras". Espírito Novo, 1934, p. 6-7.

19. Cf. CASTRO, Eduardo Viveiros de. "Os pronomes cosmológicos e o perspectivismo ameríndio", 2000, p.421-450, e também Cf. Idem. A inconstância da alma selvagem, 2002, p.486.

20. Andrade, apoiado no tradutor francês, Christian Sénéchal, concorda em ver Keyserling como um metafísico com saudade pela ação, que não pensava por pensar, mas pensava para criar. O mundo que nace e, na seqüência, Macunaíma, revelariam assim a potência construtiva da modernidade. É entretanto da cultura ocidental no momento de sua globalização que estamos, em última análise, falando. Nela, a construção falada em seu lugar. Cf. SÉNÉCHAL, Ch. "Préface du traducteur", 1927, p.7-21.

21. AGAMBEN, Giorgio. "Pour une éthique du cinéma". Trafic, 1992, p. 49-42, mais tarde incluído em GUSTAFSSON, Henrik e GRÓNSTAD, Asbjorn (ed.). Cinema and Agamben. Ethics, Biopolitics and the Moving Image, 2014, p.19-24. O projeto "A última foto", de Rosângela Rennó, é elucidativo a esse respeito. Entregou uma máquina mecânica a 42 fotógrafos cariocas com uma única diretriz: fotografarem o Cristo Redentor. Eduardo Cadava comenta: " $A$ Última Foto evokes a number of contradictions and paradoxes associated with Brazilian modernity, beginning with the role of photography in the dream of Brazilian progress. In [Elsa] Medina's words, 'Brazil is one of the mythical birthplaces of the art of fixing shadows: it is well known that Antoine Hércules Romuald Florence was the inventor of photography in Brazil, and the first-in 1824, a 
decade before John Herschelto coin the term 'photography.' It is more than fitting, then, that a Brazilian should record the death of photography." 'That there are forty-three diptychs in the series (including Rennó's) suggests that the series could continue indefinitely, however, which implies that none of these photographs are ever "the last photograph." This is confirmed in the diptych that is included in the exhibition. Produced with a Holga 120S, the image, taken by Eduardo Brandão, shows a hand that extends into the frame from the right and holds a digital camera that has the image of the redeemed Christ statue framed in its display. This is a remarkable image, not least because, in a series that references the obsolescence of analog photography, it seems to reverse the narrative that holds the works together by having an analog camera take an image of a digital camera, as if the digital existed before the analog, as if what the digital has introduced into the history of photography is already comprehended by earlier practices of photography, is already accounted for by the lens of an analog camera. Even within a series that presents itself as a lament for the passing of film photography, this work suggests that digitization is still survived by earlier modes of reproduction". CADAVA, Eduardo. "The Itinerant Languages of Photography", 2014, p. 31.

\section{AGAMBEN, Giorgio. Ideia da prosa, 1999, p.112.}

23. Idem. Mezzi senza fine. Note sulla politica, 1996, p.79-80 e, mais recentemente, Pulcinella ovvero Divertimento per li regazzi, 2015.

24. Idem. Profanações, 2007, p.25.

25. Idem. "In nome di che?", 2014, p. 72. A ideia reaparece em outro ensaio do mesmo volume, Sulla difficoltà di leggere“" (p. 81-88) e na intervenção „To Whom is Poetry Addressed?", 2014, p. 11. la na mesma proporção em que se revela, mas isso não o define, no entanto, como mero simulacro porque, se o similis exprime a semelhança (similitudo), ela é, contudo, inseparável de três fatores: da simultas, o viver juntos, da rememoração associativa do similare (relembrar), ou mesmo do gesto parasitário de simulare (copiar, imitar, fingir ou remedar) ${ }^{23}$.

Se a fotografia é exigência, é preciso destacar, porém, que essa exigência que nos interpela através das fotografias nada tem de estética. Trata-se, melhor dizendo, de uma exigência de redenção. Agamben insiste muito em seus ensaios que a imagem fotográfica é sempre mais que uma imagem: é o lugar de um descarte, de um fragmento sublime entre o sensível e o inteligível, entre a cópia e a realidade, entre a lembrança e a esperan$\mathrm{ça}^{24}$. Expande essas noções em O fogo e o relato (2014):

L'esigenza aveva per il poeta um nome: popolo. Come Dio, di cui è spesso sinonimo, il popolo è, per il poeta, sempre oggetto e, insieme, soggetto di un'esigenza. Di qui il nesso costitutivo fra il poeta e la politica e di qui la difficoltà in cui si trova presa a un certo punto la poesia. Poiché se, proprio in quanto è oggetto di un'esigenza, il popolo non può che mancare, è vero però che sulla soglia della modernità questa mancanza cresce fino a rivelarsi intollerabile ${ }^{25}$.

Em suma, ao problematizar a cara, a máscara de Carlito, Mário de Andrade retoma não só o prefácio a Macunaíma, o herói sem caráter, em que definia a rapsódia como algo além do símbolo, que não era enigma nem fábula, mas um brinquedo, um scherzo perspectivista sobre a ausência de qualidades do povo, mas, a seu modo também, resgata, fundamentalmente, os argumentos contrários ao sistema, à representação e ao lirismo, os mesmos que Céline Arnauld desenvolvera em sua resenha para Action. Macunaíma (Carlito) não tem caráter porque renuncia ao rosto em nome da máscara, a cara. E foge do fantasma porque só confia na desmemória infantil: m'amenez-y. Antecipa, assim, a tese de que a fotografia é uma profecia do corpo glorioso, que resgatamos nos versos iniciais daquele texto que Picabia, o grande parceiro de Céline Arnauld, ilustraria pouco depois do fim da guerra, Janela do caos. O poema de Murilo Mendes, uma tentativa, como diria Artaud, de acabar com o julgamento de Deus, é enunciado, com efeito, do fundo do oceano, em outras palavras, na mais completa devastação do contemporâneo.

\section{Tudo se passa}

Em Egitos de corredores aéreos

Em galerias sem lâmpadas

À espera de que Alguém

Desfira o violoncelo. 


\section{Referências}

AGAMBEN, Giorgio. Ideia da prosa. Lisboa: Cotovia, 1999.

. "In nome di che?". In: . Il fuoco e il racconto.

Roma: nottetempo, 2014.

. La comunità che viene. Turim: Einaudi, 1990.

. Mezzi senza fine. Note sulla politica. Turim: Bollati

Boringhieri, 1996.

—_. "Pour une éthique du cinéma". Trafic, no 3, p. 49-52,

1992.

. Profanações. São Paulo: Boitempo, 2007.

. Pulcinella ovvero Divertimento per li regazzi. Roma:

nottetempo, 2015.

"To Whom is Poetry Addressed?". New Observations,

no130, p. 11, 2014.

ANDRADE, Mário de. "Ainda O Garoto". Klaxon, no 5, p. 13-

14, São Paulo, 15 set. 1922.

. "Caras". Espirito Novo, a.1, no 1, p. 6-7, Rio de Janeiro, jan. 1934.

ARNAULD, Céline. "Envoi du Japon”. 391, no 15, p. 5, Paris, jul. 1921

"Le cinema. Le gosse". Action, "Hors-Série", Cahiers individualistes de Philosophie et d'art no 10, p. 4, nov. 1921.

"Le cinema. Le signe de Zorro". Action. Cabiers

individualistes de Philosophie et d'art $\mathrm{n}^{\circ}$ 10, p. 4, nov. 1921.

“Les Ronge-Bois". Projecteur, n 1, Paris, 21 mayo

1920.

"Périscope". 391, n 14, p. 6, Paris, nov. 1920.

ARTAUD, Antonin. "Point de mire par Céline Arnauld". Action: Cabiers individualistes de Philosophie et d'art, Volume 3, p.7, Paris, mar. 1922.

CADAVA, Eduardo. "The Itinerant Languages of Photography”. In: CADAVA, Eduardo e NOUZEILLES,

Gabriela (eds.). The Itinerant Languages of Photography. Princeton: Princeton University Art Museum, 2014.

CASTRO, Eduardo Viveiros de. "Os pronomes cosmológicos e o perspectivismo ameríndio”. In: ALLIEZ, Eric (ed.). Gilles 
Deleure: uma vida filosófica. São Paulo: Editora 34, 2000.

Naify, 2002.

- A inconstância da alma selvagem. São Paulo: Cosac \&

COCTEAU, Jean. Poética del cine. Buenos Aires: Cuenco de Plata, 2015.

HEMUS, Ruth. "Dada's Film-Poet: Céline Arnauld". In:

TOWNSEND, Christopher; TROTT, Alex \& DAVIES, Rhys. Across the Great Divide. Modernism's Intermedialities, from Futurism to Fluxus. Boston: Cambridge Scholars Publishing, 2014.

PASOLINI, Pier Paolo. "A poesia no cinema novo". Revista Civilização Brasileira, a. 1, n 7, p. 267-287, Rio de Janeiro, maio 1966.

SÉNÉCHAL, Ch. "Préface du traducteur". In :

KEYSERLING, Comte H. de. Le monde qui nait. Paris: Stock, 1927.

SCHLÜPMANN, Heide. The uncanny gaze: the drama of early German cinema. Chicago: University of Illinois Press, 2010.

THIEBLOT, M.J. Poaia, ipeca, ipecacuanha. A mata da poaia e os poaieiros do Mato Grosso. São Paulo: Escola de Folclore/ Livramento, 1980.

TOLIPAN et al. Sete ensaios sobre o modernismo. Rio de Janeiro: Funarte/lnstituto Nacional de Artes Plásticas,1983.

TORRE, Guillermo de. "Gestos y teorias del dadaísmo". Cosmópolis, n²6, Madrid, fev. 1921. 